\title{
A INVENÇÃO E AS REINVENÇÕES TRANSATLÂNTICAS DA “CRITICAL THEORY”*
}

\author{
The Transatlantic Invention and \\ Reinventions of "Critical Theory" \\ Laurent Jeanpierre ${ }^{* *}$
}

\begin{abstract}
RESUMO
Qual seria a origem da expressão "Critical Theory” que circula pelas universidades norte-americanas, mas sem equivalência na Europa continental? Esse artigo relata as origens intelectuais e sociais desse conceito e dessa designação, cunhados pelo filósofo alemão Max Horkheimer, em 1937, durante o exílio do Institut für Sozialforschung na América. Ele descreve também as circunstâncias do abandono desta etiqueta logo depois (e até 1968). As razões da interrupção do uso deste termo só podem ser compreendidas por meio de uma análise transnacional de um mundo acadêmico internacional. Através dela, as perguntas poderiam surgir em torno das condições subjacentes a uma posição intermediária e intercultural - e em torno do duplo status de outsider dos emigrantes. As mudanças de Adorno e de Horkheimer, ao longo de trinta anos, nas suas autoapresentações, foram o preço subjetivo a pagar para a prática de um jogo social que, acumulando os lucros de participação e de crítica, manteve um status e uma identidade, apesar da perda de suas posições, durante o exílio, e de suas reclassificações, após o regresso. As condições subjetivas sociais da "migração de conceitos" e da globalização cultural importam, especialmente, para medir as assimetrias.
\end{abstract}

Palavras-chave: circulação internacional de ideias; teoria crítica; exílio intelectual.

\footnotetext{
ABSTRACT

Where does the phrase "critical theory" that circulates on American campuses but has no equivalent in continental Europe come from? This

* Traduzido para o português por Germaine Mandelsaft.

** Professeur de l'Université de Paris VIII.
} 
article recounts the intellectual and social origins of the concept and label coined by the German philosopher Max Horkheimer, in 1937, during the exile of the Institut für Sozialforschung in America; and describes the circumstances in which it was given up soon afterwards (and until 1968). The reasons for discontinuing the use of this term can only be understood through a transnational analysis of an international academia where questions could arise about the conditions underlying an intermediate and intercultural position - and about the dual outsider status of emigrants. The switch for thirty years in Adorno's and Horkheimer's selfpresentation was the subjective price to pay in order to practice a social game that, accumulating the profits from both participation and criticism, maintained a personal status and identity despite the loss of position during exile and reclassification upon return. The subjective social conditions of the "migration of concepts" and cultural globalization are important, especially for measuring asymmetries.

Key-words: international circulation of ideas; critical theory; intellectual exile.

Nova York, no início do século XXI. A cena se passa em uma livraria universitária independente, no sudeste de Manhattan, uma das últimas deste tipo nesta cidade. Um leitor europeu, francês, por exemplo, entra na loja. Ao lado das mesas cheias de lançamentos ou de livros de arte, estantes de livros de literatura e coleções de obras reunidas de acordo com as disciplinas acadêmicas, ele se encontra frente a um conjunto de várias prateleiras com uma classificação não encontrada em livrarias e bibliotecas europeias, com exceção talvez do Reino Unido. Adorno, Agamben, Althusser, Anderson, Balibar, Bataille, Baudrillard, Benjamin, Bey, Butler, Caillois, Camus, Deleuze, Derrida, Eagleton, Jameson: esses estão entre os primeiros nomes de autores que ele vê nas prateleiras. E ainda: Rancière, Saïd, Sartre, Spivak, Virilio, Williams, Žižek, entre muitos outros. Europeus e americanos, sobretudo. Acadêmicos e escritores. Filósofos, literários e, no meio, alguns cientistas sociais - historiadores, etnólogos ou sociólogos. Quase nenhum escritor anterior ao início do século XX, com exceção, por vezes, de Engels e de Marx. Todos esses nomes e essas obras são classificados sob esse estandarte estranho: "Critical Theory", em outras palavras e traduzido para o francês, "Théorie critique", e para o português, "Teoria Crítica". O que significa essa classificação? Por que ela é utilizada, com 
frequência, nas livrarias e em bibliotecas de campi universitários e de bairros universitários nos Estados Unidos, enquanto ela raramente é utilizada na Europa, em geral, e na França, em particular?

Procuremos, para começar, nas bibliografias norte-americanas a origem dessa categorização genérica. Parece que, durante a primavera de 2008, um pouco mais de 500 livros com a menção "Critical Theory" em seu título estão listados no catálogo eletrônico da Biblioteca do Congresso em Washington: são 28 antes de 1970, 49 antes de 1980 e uns quinhentos títulos depois. Se omitimos o primeiro dos livros contendo no seu título - Outlines of a Critical Theory of Ethics de John Dewey (1891) - e suas várias reedições, a maioria das outras obras, raras, de alguns autores que utilizam o termo antes de 1970 o fazem como um equivalente à "crítica literária" ou à "crítica estética". O primeiro livro, uma exceção que usa a expressão "Critical Theory", sem referência direta ao estudo das obras, é uma coleção de ensaios, publicados em 1968, por Herbert Marcuse (18981979), filósofo alemão, exilado nos E.U.A.: Negation. Essays in Critical Theory. Esse livro é seguido por vários outros, com uma advertência similar, oriunda da mesma família de pensadores, à qual pertence Marcuse, chamada por alguns de "Escola de Frankfurt", quando não é chamada de critical theory (JAY, 1973) ${ }^{1}$ : Albrecht Wellmer (nascido em 1933) em 1971, Max Horkheimer (1895-1973) em 1972, Jürgen Habermas (nascido em 1929) e Theodor Adorno (1903-1969).

Uma pesquisa no mesmo catálogo eletrônico não sobre os títulos das obras, mas sobre os temas (através de palavras-chave, selecionadas pela Biblioteca do Congresso), conduz a resultados semelhantes, concernindo à evolução da frequência da classificação. Seja qual for o critério, parece que a expressão, bem como a classificação bibliográfica "Criticial Theory", surgiram ao mesmo tempo, a partir de 1968, para designar os primeiros

1 Já que o problema da identificação e da designação de um grupo de teóricos e de teorias está no cerne do presente trabalho, utilizaremos aqui "Institut für Sozialforschung" para nos referirmos à instituição chamada de "Escola de Frankfurt", "Teoria crítica" e outras designações, em várias línguas. Convencionalmente, essas designações são, sistematicamente, usadas entre aspas nesse artigo. Contrariamente à maioria dos comentadores e historiadores do Instituto (como em Wiggershaus, 1993, p. 637), nós não escolhemos uma apelação em detrimento de outras. Seja qual for o nome usado pelos membros do Instituto e pelos comentaristas das produções dos mesmos, é óbvio que qualquer designação sugere uma unidade fictícia e questionável (ABENSOUR, 1982, HABERMAS, 1986; VANDENBERGHE, 1998). 
livros produzidos por autores do Institut für Sozialforschung de Frankfurt, a maioria deles residente, naquele momento, na Alemanha Ocidental ${ }^{2}$.

Como a designação "Teoria Crítica" chegou a agrupar trabalhos e a identificar projetos intelectuais produzidos em outro contexto nacional, o de Frankfurt, antes de designar, posteriormente, um corpus mais amplo de produções escritas que deveriam ter uma unidade de problema ou de estilo ${ }^{3}$ ?

Uma resposta extensiva a essa pergunta deveria estimular o pesquisador a buscar uma genealogia das tradições nacionais de classificação bibliográfica e, também, a buscar os mecanismos de tradução, de recepção e de formatação de documentos trocados entre nações. Que a circulação internacional das ideias, dos conceitos e das produções teóricas seja, com efeito, submetida às estruturas sociais e aos interesses dos atores dos meios de recepção, que, portanto, se expressa por reinterpretações, transformações, mal-entendidos necessários, é hoje um resultado amplamente aceito pelos antropólogos e sociólogos (por exemplo, em: Bastide, 1954, 1960; Boltanski, 1975; Bourdieu, 2002 [1990]; Gruzinski, 1999; Lamont, 1987; Pollak, 1986; De Swaan, 1998, p. 94). No final dessas longas investigações, só nos resta questionar o modo pelo qual o significado da "teoria crítica" veio a ser, gradualmente, transformado nos Estados Unidos e a razão pela qual, enquanto designação intelectual, a expressão não foi aceita nem adotada da mesma maneira no continente europeu, especialmente nas bibliotecas e nas livrarias universitárias.

Essa forma de investigação, contudo, pressupõe que os espaços culturais, editoriais e intelectuais nacionais ou continentais sejam impermeáveis, isolados, antes de entrarem em contato uns com os outros, que eles sejam socialmente independentes e que, acima de tudo, os interesses

2 Testes bibliográficos comparáveis em revistas científicas internacionais ou nos catálogos das bibliotecas nacionais alemãs ou francesas seguem, com pouquíssimas variações, o mesmo ritmo de difusão que nos Estados Unidos. As listas de livros que ostentam a designação de "Critical Theory" e suas traduções atestam, por sua vez, que até o início dos anos 1980 esta designação será usada principalmente pelos apresentadores e comentaristas mais comprometidos com a tradição do pensamento marxista.

3 Desde 1980, a designação e a categorização "Critical Theory" perderam suas referências em favor de uma implantação local alemã e se tornaram mais gerais: elas designam um amplo conjunto de autores e de produções intelectuais. Elas não estão, automaticamente, mais ligadas a uma escola de pensamento (Frankfurt) ou a uma tradição intelectual e política (marxista). Por mais de um quarto de século, "Critical Theory" abrange, de fato, no mundo anglo-americano, outros pensadores do continente europeu, especialmente escritores e filósofos franceses, e alguns acadêmicos e intelectuais independentes dos Estados Unidos e dos países anglófonos. 
manifestados sejam definidos a nível nacional (ou continental). O caso que nós examinamos aqui, ou seja, a circulação de uma das categorias de definição e "autoapresentação" do Institut für Sozialforschung, exige, no entanto, o questionamento dessas pressuposições.

Com efeito, a designação alemã "Kritische Theorie" foi cunhada pela primeira vez em 1937, por Max Horkheimer, durante o seu exilio norte-americano, por ocasião da publicação, em Paris, de um artigo no Zeitschrift für Sozialforschung, a revista do Instituto: de imediato, ela foi um produto transnacional e, mais especificamente, transatlântico. O reaparecimento desta etiqueta, na década de 1960, pode ser considerado também um fenômeno de ordem transatlântica, pois, simultaneamente, publicam-se obras traduzidas do inglês para o alemão e vice-versa, alguns meses ou anos depois, nos E.U.A. e na Alemanha.

Baseando-nos no que é demonstrado, sob diversas formas bem diferentes umas das outras, uma parte da antropologia contemporânea da globalização cultural (AMSELLE, 2001; APPADURAI, 2005; ASSAYAG, 1998, 2000; BHABHA, 1994; CLIFFORD, 1997; HANNERZ, 1996), no que se refere a outras produções simbólicas, devemos partir do pressuposto segundo o qual toda genealogia da "Critical Theory" deve levar em conta o caráter transnacional do contexto da emergência e da difusão da teoria crítica alemã.

A investigação que desenvolvemos aqui recorre a um desvio histórico, o período antes da década de 1960. Com efeito, sabemos que a expressão "teoria crítica" foi forjada em 1930 por Horkheimer; trata-se, portanto, de compreender as causas do seu ressurgimento, quase simultâneo, na Alemanha e nos Estados Unidos, por volta de 1968. Procuraremos interrogar seu desenvolvimento anterior. As trajetórias de Adorno e de Horkheimer (apesar de outras figuras serem brevemente evocadas), as tomadas de posições dos mesmos e os usos que eles fizeram dessa designação constituem nosso principal objeto. A pesquisa baseia-se na historiografia recente da "Escola de Frankfurt", notadamente na experiência do exílio de seus membros do outro lado do oceano Atlântico, a partir de 1934 (FLECK, 2007, p. 264-427; JAY, 1977, 1986; SCHMIDT, 2007; WHEATLAND, 2003, 2004a, 2004b, 2005; WIGGERSHAUS, 1993) e do retorno para a Alemanha Ocidental de Adorno e Horkheimer (ALBRECHT et al., 1999; SÖLLNER, 2002, 2005).

Pois, se as histórias institucional e intelectual do Institut für Sozialforschung foram objeto de várias pesquisas ou sínteses (ASSOUN, 1987; 
DUBIEL, 1985; JAY, 1977, 1986; SÖLLNER, 1979; WIGGERSHAUS, 1993), as relações internacionais dos membros do Instituto foram negligenciadas - por exemplo, as suas interações com os grupos de acadêmicos, de intelectuais, de representantes de associações ou de comentaristas norte-americanos (WHEATLAND, 2003). E enquanto os processos de globalização cultural são, geralmente, estudados em escala macro-histórica ou macrossociológica, um conhecimento mais detalhado das condições microssociológicas desses processos e dos perfis dos atores capazes de conduzi-los ou impedi-los ainda faz falta.

As variações do emprego da etiqueta "Teoria Crítica" nos Estados Unidos e na Alemanha, por Adorno e Horkheimer, a partir da década de 1930 até os anos 1960, são analisadas, aqui, como estratégias de "autoapresentação", no contexto das relações filosóficas e científicas nacionais e internacionais. Trata-se de restituir, por meio da análise histórica, as "funções de interesse" cumpridas por essas estratégias e o contexto social do qual dependiam (BOLTANSKI, 1975). Neste caso preciso, esse contexto foi marcado pela experiência do exílio e pelo sentimento subjetivo que ela provoca. Esse sentimento não foi dissipado pelo retorno de Adorno e de Horkheimer à Alemanha, em 1950: o exilado que "volta ao país" vive, uma segunda vez, a condição de um estrangeiro (SCHÜTZ, 2003). Ora, a situação de exílio, especialmente durante uma Guerra Mundial, engendra um desajustamento entre o indivíduo e seu meio social, ou seja, uma verdadeira crise de identidade ${ }^{4}$.

Toda trajetória de exílio coloca o indivíduo em uma posição múltipla de intermediário entre vários grupos, espaços sociais e entre culturas. Ela destaca problemas de preservação da identidade que, geralmente, não são tão salientes na vida cotidiana. No entanto, se as ciências sociais tendem a pressupor a existência dessa constância de si mesmo e da ação do sujeito, esse sentimento não é dado: ele resulta de uma atividade dos indivíduos, a fim de reunir investimentos distintos, e até mesmo opostos, das filiações sociais múltiplas (BASTIDE, 1955; POLLAK, 1992 [1984], 2000). Tal atividade visa construir uma "identidade para o Outro" que suporta a forma como somos designados e como nós nos representamos (HEINICH, 1995).

4 Aqui, "identidade" não quer dizer qualquer propriedade substancial dos agentes sociais, nem mesmo uma função da afiliação dos mesmos a um grupo, mas, sim, continuidade e permanência. 
A análise do trabalho identitário possibilita a descrição das diversas maneiras de preencher a brecha que existe em toda experiência social - regular ou crítica - entre grupo de afiliação e grupo de referência, entre "espaço vivido" e "espaço investido" (JEANPIERRE, 2004)5. As estratégias de "autoapresentação" de intelectuais emigrantes fazem, basicamente, parte desse trabalho. Todas elas não são idênticas.

No caso de Adorno e de Horkheimer, tentaremos mostrar como suas estratégias de "autoapresentação", ligadas a uma certa utilização do rótulo " teoria crítica “, podem só ser compreendidas se esses dois indivíduos forem considerados intermediários culturais, dentro de um espaço transatlântico, e não representantes marginalizados de uma tradição cultural nacional, em exílio "permanente" (JAY, 1986) da década de 30 aos anos 60. A eclipse da etiqueta "teoria crítica", durante todo esse período, é o produto das limitações dessa posição particular de intermediários ocupada por esses dois [intelectuais]. E o renascimento da teoria crítica, no final dos anos 60, é uma reação às perdas do monopólio da utilização dessa etiqueta. Mas, antes de fazer essa demonstração, convém retornar ao contexto do surgimento da etiqueta "Kritische Theorie".

\section{A construção e a crise de uma identidade}

\section{“KRITISCHE THEORIE”: DO CONCEITO À ETIQUETA}

As primeiras obras publicadas no final dos anos 1960, nos Estados Unidos e na Alemanha, com a designação de "Teoria Crítica", retomam os trabalhos escritos por Horkheimer nos anos 1930. Entre eles, encontra-se

5 Graças a esse par de conceitos, podemos evitar lidar com a migração, através do esquema espaço de origem/espaço de chegada. Ele se adequa, portanto, a uma análise que tenta entender os efeitos intelectuais de uma migração internacional, deixando de lado a escala nacional: "Para definir esses dois conceitos, podemos dizer que o espaço vivenciado é o ambiente físico onde se desenvolve a existência material cotidiana do migrante, isto é, o espaço de acolhimento. O espaço investido, por sua vez, é o lugar onde, supostamente, estão encarnados os objetivos do indivíduo" (ROSENTAL, 1990, p. 1408). 
Teoria tradicional e teoria crítica, de 1937, estabelecendo as primeiras definições do conceito que, posteriormente, sustentará essa designação (HORKHEIMER, 1974, p. 15-92). O alvo principal do autor é constituido pelas epistemologias dominantes das ciências naturais e das ciências sociais de sua época, agrupadas sob o título genérico de "teoria tradicional". Elas incluem tanto Descartes quanto Poincaré, tanto Hermann Weyl quanto Edmund Husserl, tanto Emile Durkheim quanto Max Weber. Na opinião de Horkheimer, além de suas diferenças, essas epistemologias surgem do pressuposto de que existe uma possível identidade entre o conhecimento e a realidade. Portanto, elas imaginam o produto do conhecimento como o alinhamento das propostas inferidas da experimentação.

$\mathrm{O}$ "conceito tradicional de teoria [...] vai em direção a um sistema puro de sinais matemáticos" (Ibid., p. 15, 18). Por um lado, a "teoria tradicional" relega a atividade teórica a uma mera formação de "pressupostos", em relação a uma ordem de fatos, já dados na realidade. Por outro lado, ela não leva em conta o lugar da atividade científica na divisão do trabalho e da sua função social. Pois, além dos conflitos que possam existir em todas as disciplinas do conhecimento, ou entre as diferentes disciplinas, toda ciência tenta manter, antes de mais nada, a "sociedade tal como é" (Ibid., p. 36-37).

A "teoria crítica", ao contrário, pretende estabelecer uma relação diferente entre os conhecimentos positivos e a filosofia, mas também entre a atividade teórica e acadêmica e as outras práticas sociais. Ela se baseia na ideia de que não só o dado "natural", a totalidade do mundo perceptível, mas também os órgãos de percepção e as atividades do espirito são, sobretudo, produtos cristalizados da prática humana e da história. Isso implica que o sujeito sábio não pode ser pensado como diferente e separado de seu objeto de estudo. A "teoria crítica" visa, então, alcançar outro conhecimento, bem como uma transformação dos sujeitos a serem conhecidos. Ela também pretende estabelecer uma relação entre o conhecimento e a ação que não seja regida, exclusivamente, pelo utilitarismo. $O$ teórico crítico não é neutro, como é ou acredita ser o erudito, nem tampouco está enraizado em uma comunidade fictícia, tal, por exemplo, o propagandista nazista, de acordo com Horkheimer. A "teoria crítica" tenta estabelecer uma esfera de pensamento e de ação específica irredutível às disciplinas acadêmicas existentes, mas também ao ativismo político (ASSOUN, 1987, p. 4). No entanto, ela supõe uma ligação com "interesses políticos" (HORKHEIMER, 
1974, p. 57), uma vez que ela visa "acelerar a evolução" em direção a uma sociedade justa (Ibid., p. 55), intensificando os conflitos sociais (Ibid., p. 53) e estabelecendo, concretamente, sem idealismo ou utopismo, "uma ordem social em conformidade com a Razão" (Ibid., p. 28).

Desde o início, e em conformidade com a história anterior do Instituto de Pesquisa Social (Institut für Sozialforschung), em Frankfurt, a "teoria crítica" está, portanto, mais ligada ao pensamento marxista que ao movimento comunista. Aliás, se o mundo dos fatos observáveis e se as capacidades de observação e de análise desse mundo são, segundo Horkheimer, os produtos do trabalho humano acumulado, isso significa que o sujeito e, também, o objeto do conhecimento são, em última análise, dependentes do "modo de produção" econômico, da mesma maneira que a atividade de conhecimento está, obrigatoriamente, incluída na divisão do trabalho, estabelecida pela organização social dominante. No lugar de uma "crítica idealista da razão pura", inspirada em Kant, a "teoria crítica", portanto, deve se basear em uma "crítica dialética da economia política" (Ibid., p. 38). Assim redefinido, em 1937, nos Estados Unidos, o programa intelectual do Instituto substitui os projetos de pesquisa sociológica e econômica que foram dominantes, antes de Horkheimer assumir a liderança em 1931. Esse programa substitui, também, a "filosofia social" e a "teoria materialista", que Horkheimer havia transformado em uma nova palavra de ordem coletiva, antes do seu exílio (HORKHEIMER, 1968; WIGGERSHAUS, 1993, p. 177). A "teoria crítica" implica a reconciliação da pesquisa empírica em ciências sociais com a filosofia social e política, inspirada pelo materialismo, ficando à distância de todo tipo de positivismo.

Falar de "teoria crítica", em 1937, equivalia a um gesto filosófico e científico que tinha, também, uma função social e política. Tratava-se de reunir pesquisadores que haviam partido de Frankfurt após o fechamento do Instituto e a demissão de Horkheimer pelas autoridades nazistas. No período de 1933 a 1950, esses pesquisadores haviam se espalhado entre os vários escritórios do Instituto, em Genebra, Paris, Londres e Nova Iorque (WIGGERSHAUS, p. 121-142). Com efeito, naquela época, não existia nenhuma outra designação disponível para descrever a unidade de pesquisas deste Instituto. A ideia que este Instituto pudesse criar e abrigar um novo método ou uma escola de pensamento autônoma e específica surgiu após a partida forçada de Frankfurt. "A própria expressão 'Escola de Frankfurt' 
só foi utilizada após o retorno do Instituto para a Alemanha" (JAY, 1977, p. 11), ao mesmo momento em que a designação concorrente ou redundante de "Teoria Crítica" fazia seu reaparecimento.

Essa nova autodefinição também foi utilizada para mostrar ao público intelectual francês e alemão da França, onde o texto inaugural de Horkheimer foi publicado (durante o Front Populaire ${ }^{6}$ ), que existia uma resistência filosófica alemã, antes de se decidir sobre o paradeiro geográfico final dos membros do Instituto 7 . Forjada para enfrentar uma crise de identidade profissional e política, especificamente alemã, a designação de "Teoria Crítica" foi, portanto, também o produto de uma estratégia de relações públicas em um espaço intelectual internacional.

\section{A CRISE DA "TEORIA CRÍTICA"}

Um estudo das histórias do Instituto e das bibliografias de seus membros, próximos ou distantes, demonstra que os usos da etiqueta "Teoria crítica" se modificaram de acordo com diferentes períodos (JAY, 1977; WIGGERSHAUS, 1993). Definido e discutido em 1937, o conceito de "teoria crítica" deixou, praticamente, de ser utilizado pelos membros do Instituto, nos Estados Unidos, após essa data. A volta de Horkheimer e de Adorno para a Alemanha, em 1950, não provocou a reativação da designação. A partir de meados dos anos 1950, a "teoria crítica da sociedade" foi ocasionalmente mencionada em um ou em outro artigo, mas essa expressão nunca foi citada nos títulos e subtítulos de artigos ou de obras dos membros do Instituto.

Embora, em 1963, Adorno tenha reunido diversos artigos em um livro intitulado Modelos críticos (Kritische Modelle) (2003a), essa designação de "teoria crítica" só reapareceu, na sua totalidade, com a publicação, na Alemanha, de uma coleção de dois volumes de Max Horkheimer, intitulada

6 Nota da tradutora: Front Populaire designa a coalizão de esquerda, que, tendo à frente Léon Blum, governou a França entre 1936 e 1937.

$7 \quad$ Na verdade, a França, era ainda uma terra de asilo para muitos alemães perseguidos pelo nazismo e forçados ao exílio, ou para adversários políticos. Sabemos que, além da Biblioteca Felix Alcan, que publicava, nessa época, a revista do Instituto, Maurice Halbwachs, Celestin Bouglé e o jovem Raymond Aron encontraram e acolheram alguns membros, incluindo Walter Benjamin, no Centro de Documentação Social da École Normale Supérieure (WIGGERSHAUS, 1993, p. 126-127). 
Kritische Theorie. Eine Dokumentation (1968), e preparada por seu aluno, Alfred Schmidt (nascido em 1931). A partir desta data, em ambos os lados do Atlântico, as etiquetas "Kritische Theorie" e "Critical Theory", assim como a etiqueta "Escola de Frankfurt", também foram utilizadas fora do Instituto, e não apenas por seus partidários. Como podemos, então, explicar o abandono dessa designação, durante quase trinta anos, tanto nos Estados Unidos como na Alemanha?

Para melhor entender este desaparecimento, é preciso examinar, primeiro, a situação de exílio de Horkheimer e, mais tarde, o exílio de Adorno nos Estados Unidos. É como se o contexto social de recepção do Instituto, nos Estados Unidos, tivesse provocado o declínio do conceito e da etiqueta "Teoria crítica". Contudo, tanto a historiografia da "Escola de Frankfurt" como os testemunhos retrospectivos dos protagonistas transmitiram a imagem de um Adorno e de um Horkheimer como críticos mais ou menos visionários da sociedade americana: notadamente, da industrialização dos bens culturais (ADORNO; HORKHEIMER, 1974 [1944], p. 129-176) ${ }^{8}$ e dos usos reguladores e "modernizadores" das ciências sociais empíricas (ADORNO, 2003a [1963], p. 265-300). Esses dois fenômenos ocorreram na década de 1940, antes de atingir a Europa, após a Guerra Fria. Os biógrafos, e especialmente os de Adorno, confirmaram, em ambos os lados do Atlântico, essa representação (CLAUSSEN, 2003; JÄGER, 2003; JENEMANN, 2007; MUELLER-DOOHM, 2004). Minima Moralia, os famosos fragmentos de uma "vida mutilada", escritos no exílio por Adorno e publicados logo após o seu regresso na Alemanha Ocidental ${ }^{9}$ e, especialmente, a Dialektik der Aufklärung, obra igualmente invisível nos Estados Unidos e que foi, finalmente, publicada na Alemanha em $1969^{10}$, foram, a esse respeito, testemunhos dessa consciência crítica dos filósofos exilados, que permaneceu intacta, e da resistência dos mesmos às normas da sociedade americana.

Em outras palavras, o desuso da designação "Teoria crítica" não mudou em nada a atitude crítica geral dos pensadores de Frankfurt, exceto,

\footnotetext{
8 Como exemplo dessa crítica, doravante associada.

9 ADORNO, Theodor W. Minima Moralia. Reflexionen aus dem beschädigten Leben. Berlin: Suhrkamp, 1951.

10 HORKHEIMER, Max; ADORNO, Theodor W. Dialektik der Aufklärung. Philosophische Fragmente. Frankfurt-am-Main: S. Fischer, 1969.
} 
talvez, no que diz respeito a Marx e à tradição marxista revolucionária, revogada durante o exílio (JAY, 1977; WIGGERSHAUS, 1993).

A análise histórica mais recente sobre o comportamento de Adorno e de Horkheimer, sobretudo durante o exílio, em relação às indústrias culturais e às pesquisas empíricas em ciências sociais, contribui para qualificar essa opinião e para questionar a lógica das variações das suas posições e das suas "autoapresentações". Era sabido que Marcuse e outros membros do Instituto, como Franz Neumann, participaram do esforço de guerra norte-americano, notadamente a serviço do Office of Strategic Services (KATZ, 1989). Sabemos que essa participação foi determinada, em parte, pela decisão tomada por Horkheimer, no início dos anos 1940, de que o Instituto já não podia mais sustentar, financeiramente, a maioria de seus membros, exceto o núcleo de base do qual ele fazia parte com alguns outros, entre eles, Adorno. Apesar das diferenças econômicas e profissionais de inserção na sociedade americana, as atitudes de Adorno e de Horkheimer no exílio não se revelam nem mais nem menos hostís aos Estados Unidos como parecem. Para entender esta ambivalência dos comentaristas da "Escola de Frankfurt", desconhecida durante muito tempo, é preciso ressituá-la no contexto social específico, por natureza transnacional, de toda situação de exílio. É o preço a pagar para entender a razão pela qual a "teoria crítica" teve que ser reinventada, nos anos 1960, nos Estados Unidos e em Frankfurt.

\section{A "Teoria crítica” no exílio}

\section{SITUAÇÃO DE EXÍLIO E REFLUXO DA CRÍTICA}

Primeira observação: o desuso progressivo da designação "Teoria crítica", durante o exílio americano dos membros do Instituto, consiste em uma atitude muito menos distante que é, geralmente, percebida em relação às "indústrias culturais". Em 1948, por exemplo, em uma carta a Fritz Lang, Horkheimer propôs um roteiro para uma biografia cinematográfica de Thomas More, no espírito do diretor alemão exílado William Dieterle, amigo e vizinho, em Los Angeles, de Horkheimer (SCHMIDT, 2007, p. 75) e também 
autor de filmes sobre Pasteur e Benito Juarez, ambos realizados no exílio (GIOVACCHINI, 2001, p. 87). Aliás, Dieterle, cineasta bem-sucedido, tinha sido convidado, alguns anos antes, a escrever na revista Studies in Philosophy and Social Sciences - vitrina do Instituto nos Estados Unidos -, dedicada à comunicação de massa. Nela, ele diz que estava convencido de que a indústria do cinema e da cultura de massa era potencialmente democrática. Em uma carta que escreveu, em 1942, para Leo Lowenthal, outro membro exilado do Instituto, Horkheimer também parecia admitir que as indústrias culturais e a cultura popular incluíam, no duplo sentido do termo, um elemento utópico. Ele escreveu: "não podemos culpar as pessoas por serem mais interessadas pela intimidade e pelo consumo do que pela produção; essa característica tem um elemento utópico. Na utopia, a produção não desempenha um papel decisivo. É a terra da abundância" (citado em JAY, 1986, p. 52).

O projeto do filme sobre More, que ele enviou a Lang, representou, neste contexto, para o público americano, os conflitos entre os engajamentos mundanos e o amor à verdade, em uma época marcada pelas guerras de religião, e comparável, segundo Horkheimer, à época da Guerra Fria e do macartismo (GIOVACCHINI, 1998). O nível de independência da atividade intelectual, em relação às necessidades externas ao mundo intelectual, fossem elas políticas (como foi o caso de muitos cidadãos e intelectuais a partir da entrada dos Estados Unidos na guerra ou, ainda, a partir do início da Guerra Fria) ou econômicas (como foi o caso da maioria dos exilados europeus), não representou, para Horkheimer, apenas uma obsessão teórica, durante esse período.

A atitude ambivalente dos dois filósofos de Frankfurt em relação à prática norte-americana das ciências sociais empíricas - área estratégica para a delimitação do projeto intelectual da "teoria crítica" - se explica pelo nível de autonomia conquistada. Com efeito, entre a chegada de Adorno nos Estados Unidos, em 1938, e o ano de 1950, investimentos e reduções na pesquisa empírica alternaram-se. As causas dessas oscilações foram, essencialmente, econômicas: a crise financeira americana e uma gestão, em parte perigosa, após a expatriação dos fundos do Instituto, fora da Alemanha no início da década de 1930, reduziram seus próprios recursos. A partir de 1939, Horkheimer reduziu, drasticamente, as operações do Instituto e cancelou os salários da maioria dos funcionários. A partir de 1941, ele se mudou para Los Angeles, sozinho no início da sua estadia, com o intuito de 
se dedicar exclusivamente à escrita filosófica, conservando para o pessoal administrativo (para ele e para alguns íntimos - entre eles, Adorno, Pollock e Lowenthal) os juros derivados dos fundos do Instituto e as quantias pagas pelos organismos de financiamento americanos. A estratégia de Horkheimer consistiu, então, em propor projetos de pesquisa, cujo único objetivo seria obter financiamentos adicionais por parte das fundações filantrópicas americanas, inclusive da Fundação Rockefeller (WIGGERSHAUS, 1993; WHEATLAND, 2004b) para o Instituto. A atitude, digamos, crítica de Adorno e de Horkheimer, no que diz respeito à pesquisa norte-americana em ciências sociais e a seus métodos, foi provocada pelos resultados variáveis dessa estratégia.

No entanto, seria errado imaginar que esse comportamento só se tornou necessário por causa das obrigações sociais do meio acadêmico americano e do exílio. De fato, os pesquisadores do Instituto já haviam elaborado e produzido vários estudos empíricos antes das partidas para os Estados Unidos, notadamente Studien über Autorität und Familie, publicados um ano antes da invenção da ideia de "teoria crítica" (WIGGERSHAUS, 1993, p. 132-135). Aliás, se a Universidade de Columbia concordou em abrigar, gratuitamente, o escritório do Instituto em Nova Iorque, foi precisamente na esperança de que essa colaboração ajudasse a restaurar a posição de seu Departamento de Sociologia frente à sociologia empírica, cuja supremacia foi conquistada, em 1930, pela Universidade de Chicago (WHEATLAND, 2004a). O sociólogo austríaco Lazarsfeld, correspondente em Viena e pesquisador associado do Institut für Sozialforschung antes do seu exílio nos Estados Unidos, em 1937 (WHEATLAND, 2005; FLECK, 2007, p. 265), tornou-se, a partir do ano seguinte, um intermediário essencial entre o círculo de Horkheimer e o establishment das fundações e da pesquisa nos Estados Unidos. Por exemplo, foi graças a ele que Adorno pôde emigrar para a América em 1938, a fim de participar de uma pesquisa sobre a rádio, encomendada pela Universidade de Princeton e conduzida por ele (WIGGERSHAUS, 1993; WHEATLAND, 2005). Assim, um relacionamento ininterrupto existiu entre Horkheimer, Adorno e Lazarsfeld durante o exílio dos mesmos. Aliás, Lazarsfeld foi considerado um dos jovens sociólogos mais inovadores, em termos de métodos de pesquisa empírica e de contratos de pesquisa (MORRISON, 1978; POLLAK, 1979). 
No entanto, ao contrário do que foi retido pela historiografia, a relação entre esses três pesquisadores ${ }^{11}$ não se manifestou por uma oposição frontal, mas por uma prática em conjunto da sociologia e da psicologia empírica, pelo menos até novembro de 1941, quando Adorno se mudou para Los Angeles para se encontrar com Horkheimer (WHEATLAND, 2005). Entre 1943 e 1950, Adorno participou, com ex-colaboradores de Lazarsfeld (Marie Jahoda, por exemplo) e com pesquisadores americanos, dos estudos sobre o antissemitismo conduzidos pelo Instituto e financiados pelo American Jewish Committee. Esse contrato foi fechado, em parte, graças à informação e à intercessão do sociólogo austríaco (Ibid.). Um estudo detalhado das produções de Adorno e de Horkheimer no exílio mostraria como o compromisso dos mesmos com as pesquisas empíricas em ciências sociais, na década de 1940, foi constante e importante, envolvendo muitas colaborações. Pesquisas de opinião, questionários, testes projetivos TAT (Teste de Apercepção Temática) e de Rorschach, entrevistas individuais e grupais, análise dos conteúdos de entrevistas: nenhuma dessas novas técnicas de investigação psicológica e sociológica, dos anos 1940, foi ignorada por Adorno e por Horkheimer. Esse compromisso com a pesquisa empírica não foi periférico ou somente provocado pela necessidade: ele determinou a redefinição do projeto intelectual do Instituto e de seus modos de autoapresentação junto ao mundo acadêmico norte-americano. Ora, todas essas escolhas foram inseparáveis da verdadeira natureza do relacionamento mantido pelos dois filósofos alemães, durante esse período, com Lazarsfeld. Portanto, vale a pena insistir nesta questão, a fim de melhor entender a maneira pela qual Adorno e Horkheimer redefiniram suas identidades no exílio, deixando de lado a referência ao projeto da "teoria crítica".

11 Grande parte dessa historiografia (MORRISON, 1978, POLLAK, 1979) foi dependente dos testemunhos dos próprios Adorno e Lazarsfeld (ADORNO, 2003a [1963], p. 265-300; LAZARSFELD, 1969), sem questionar a função social para si e para o Outro dos depoimentos e histórias de vida retrospectivos. Esses pesquisadores foram sobredeterminados pelos interesses em jogo nas ciências sociais alemãs e americanas, no final dos anos 1960, e pela posição dos Estados Unidos na internacionalização das ciências sociais e de seus métodos naquele período. Lazarsfeld tendeu a minimizar a diversidade dos seus velhos compromissos científicos e metodológicos e reconstruiu um percurso linear da sua própria trajetória, que o levava, quase naturalmente, a defender a pesquisa quantitativa aplicada (FLECK, 2007). Adorno, por sua vez, superestimou a sua velha incapacidade de se adaptar à sociedade americana; ele também subestimou o acordo mínimo sobre meios e fins que era necessário para sua colaboração com Lazarsfeld, entre 19381941, e a extensão de seu envolvimento no projeto de pesquisa sobre a rádio de Princeton (Ibid.). 


\section{Retorno sobre uma controvérsia: Adorno contra Lazarsfeld}

No contexto da pesquisa sobre a rádio, realizada pela Universidade de Princeton e coordenada por Lazarsfeld, a partir de 1937, Adorno foi encarregado da análise de programas de música nas ondas americanas. A candidatura de Adorno foi aceita pelas fundações americanas que patrocinaram a pesquisa e pelos pesquisadores que, anteriormente, tinham contratado Lazarsfeld, porque Adorno havia sido responsável, em Frankfurt, pelos programas de música na rádio, muito semelhantes, antes de seu exílio (FLECK, 2007, p. 283). Contudo, após um ano e meio e um primeiro memorando, escrito em junho de 1938, o filósofo alemão contestou as modalidades práticas da pesquisa conduzida pelo projeto. Em On a Social Critique of Radio Music, escrito em 1939, Adorno denunciava, além da radiodifusão, a "pesquisa administrativa" (administrative research), como era chamada por Lazarsfeld (1941). Ele contrapunha essa maneira de elaborar ciências sociais à necessidade de se fazer uma "pesquisa empírica crítica" (critical empirical research). Mas, a diferença entre essas duas abordagens residia mais nas finalidades do que nos métodos: em última análise, trabalhar para o American Jewish Committee seria mais nobre do que trabalhar para estações de rádio privadas (FLECK, 2007, p. 308).

Para Adorno, a necessidade de produzir dados para esses patrocinadores proibia, de fato, a formulação de interpretações e o questionamento do sistema de mídias privadas (ADORNO, 2003a [1963]). Para Horkheimer, a psicanálise freudiana era mais válida, epistemologicamente falando, do que a psicologia empírica ou experimental que, segundo ele, dava uma importância exagerada à opinião consciente e espontânea, sem questionar seus métodos de produção e de acondicionamento. Apesar dessas tensões, Lazarsfeld continuou defendendo, frente às fundações e aos patrocinadores do projeto, a exigência de uma abordagem crítica da pesquisa empírica e a legitimidade das produções de Adorno. Em vez de se afastar do projeto, ele ainda colaborou com ele dois anos após emitir suas reservas. Em menos de um ano, após ter denunciado a radiodifusão de músicas, ele também se entusiasmou quando foi convidado para animar, todos os domingos, uma hora de vulgarização musical na WNYC, uma rádio de Nova York (ADORNO, 2003b, citado por FLECK, 2007, p. 320). E após seu retorno a Frankfurt, no início dos anos 1950, Adorno defendeu as pesquisas de opinião e de- 
nunciou a oposição entre a pesquisa social "administrativa" e a pesquisa social "crítica" como sendo uma "simplificação" (JAY, 1986, p. 124-125).

Por trás do conflito, mais ou menos latente, entre Adorno e Lazarsfeld, na década de 1940, e por trás das atitudes distintas, mas variáveis, de ambos no que dizia respeito aos métodos da pesquisa empírica e, especialmente, aos seus objetivos, existia, na realidade, uma luta entre duas personalidades cujos respectivos status hierárquicos foram invertidos pela experiência do exílio. Esse contexto pôde explicar as queixas de Adorno, especialmente junto aos "oficiais" da Fundação Rockefeller, contra a ilegitimidade de Lazarsfeld para dirigir, corretamente, o projeto de pesquisa sobre a rádio: Adorno, que vinha de uma família burguesa, se identificava com uma posição social e intelectual superior à de seu colega austríaco, cuja origem social o remetia à pequena burguesia e a um judaísmo periférico (POLLAK, 1979, FLECK, 2007).

\section{Posições de intermediário e recalque da etiqueta "Teoria crítica"}

A ambivalência de Adorno em relação a Lazarsfeld e a sua forma de fazer ciências sociais, bem como a sua ambivalência em relação à mídia radiofônica como veículo de uma industrialização perigosa da cultura, baseavam-se mais amplamente numa estratégia de duplo jogo social, consistindo, em ambos os casos, em tentar combinar os benefícios do investimento e os benefícios da crítica das formas de investimento mais rentáveis nessas duas áreas. Já que, depois de 1941, Adorno e Horkheimer tiveram uma maior autonomia econômica e se decepcionaram com os investimentos sociais nos E.U.A., sobretudo quando os dois se comparavam com o sucesso dos investimentos de Lazarsfeld - mesmo se este último, antes de sua chegada nos Estados Unidos, tinha menos posses -, eles tendiam a assumir posições críticas ou a reativar, apenas nas formas eufemísticas, a designação de "teoria crítica" - como acontecia também com a noção de "pesquisa empírica crítica".

Assim, o recalque da designação "teoria crítica" pelos filósofos de Frankfurt exilados pode ser interpretado como o preço a pagar pelas 
estratégias sociais de investimento nos espaços universitários, intelectuais e culturais da América do Norte. Em 1946, Marcuse observou, por exemplo, que há muito tempo Horkheimer sentia aversão à própria expressão de "teoria crítica", como também à referência à luta de classes (WIGGERSHAUS, 1993, p. 379, 382).

No entanto, apesar de terem abandonado essa etiqueta, os teóricos de Frankfurt não pararam de criticar, de maneira intermitente ou privada, as instituições científicas e culturais dos Estados Unidos. Embora a atividade de escrita de Adorno e Horkheimer, no exílio, já não tivesse mais o nome de "teoria crítica", ela aparecia como a necessária racionalização das aspirações desajustadas do mundo social norte-americano. Vários outros comportamentos deste período traduziram também uma dupla atitude em relação à sociedade norte-americana e à situação de exílio. Por exemplo, embora fossem cidadãos americanos, ao contrário de Brecht e Eisler (Ibid., p. 371), os dois filósofos desenvolveram a ideia de não assimilação à sociedade americana e a suas exigências e criticaram os emigrantes, como Lazarsfeld - que pretendiam integrar a sociedade de acolhimento ${ }^{12}$.

No entanto, a decisão de Adorno e Horkheimer de voltar para a Alemanha, após 1950, não alterou, por vários anos, a ambivalência dos mesmos em relação à sociedade americana e nem tampouco às "indústrias culturais" e aos métodos empíricos de pesquisa em ciências sociais. Quanto à designação de "teoria crítica", ela permaneceu oculta após essa data. Pró-americanismo objetivo, antiamericanismo subjetivo, desenvolvimento de um discurso crítico e rejeição do estandarte de "Teoria Crítica": essas posições, consolidadas no exílio, formaram uma constelação de solidariedade que Adorno e Horkheimer mantiveram, em níveis diferentes, segundo cada um, do início da década de 1940 até os anos 1960. É por isso que Horkheimer se opôs, no contexto da Guerra Fria, à republicação da série completa da revista do Instituto, publicada antes da guerra e que ficou escondida em um armário trancado, numa sala do novo domicílio do Instituto, a partir de

12 "Queremos nos livrar dos controles, nos mantermos independentes, determinarmos, nós mesmos, o conteúdo e a forma da nossa produção! Nós somos imorais. Quem se assimila pode, ao contrário, pelo menos de vez em quando, ser extravagante, até mesmo na política. Mas neste caso, como em muitos outros, integrar-se significaria, primeiramente, se submeter, se submeter muito, dar garantias materiais que a submissão é inteira, duradoura e irrevogável". Carta de Horkheimer a Adorno, 21 de junho de 1941 (citada por WIGGERSHAUS, 1993, p. 266). 
1950 (Ibid., p. 530). A estratégia de Horkheimer consistiu em elaborar uma posição sólida nas ciências sociais, dentro da universidade alemã, contando com a ajuda das fundações filantrópicas e das autoridades militares norte-americanas, mas sem abandonar, durante vários anos, a presença física e intelectual do Instituto nos Estados Unidos (Ibid., 1993, p. 391).

$\mathrm{Na}$ Alemanha Ocidental, em reconstrução, Horkheimer e Adorno ocuparam, rapidamente, posições acadêmicas importantes - uma raridade entre os ex-emigrantes. Assim que retornou a Frankfurt, Horkheimer foi reintegrado como professor de Filosofia e de Sociologia e, em seguida, designado reitor da Faculdade de Filosofia. Posteriormente, ele ocupou posições influentes, no mundo das elites locais e nacionais. Embora muito subestimada, a influência política e pública dos dois filosófos não deixou de ser significativa junto às elites políticas e às mídias - rádio e televisão (ALBRECHT et al., 1999). Mas essas trajetórias ascendentes foram fortalecidas, principalmente, por elas se articularem a uma posição de intermediários e de passadores privilegiados entre as fontes de financiamento: as autoridades americanas e a Alemanha em processo de reconstrução e de desnazificação.

O contexto político da Guerra Fria e o contexto da dependência econômica da Alemanha com os fundos americanos do Plano Marshall garantiram lucros a essas posições. Como corolário, as limitações subjetivas ligadas à ocupação dessas posições explicaram o recalque contínuo da etiqueta "Teoria Crítica", por mais de uma década, após o regresso de Adorno e de Horkheimer.

Se deixarmos de lado a publicação de Adorno em Monat, a revista criada, em 1948, pelo Congresso para a Liberdade Cultural (WIGGERSHAUS, 1993, p. 396), as tomadas de posições na área das ciências humanas e sociais eram, provavelmente, ainda as mais emblemáticas dessa função de intermediários transatlânticos assumidas por Adorno e Horkheimer e os lucros associados aos mesmos. Por exemplo, logo após seu retorno, Horkheimer foi encarregado pela Library of Congress de fazer um mapeamento da sociologia alemã que pudesse servir para orientar os investimentos americanos (HORKHEIMER, 1952).

Entre 1950 e 1952, Adorno coordenou estudos de comunidades, no Instituto de Pesquisa em Ciências Sociais de Darmstadt, da mesma maneira que a Escola de Chicago. Essas pesquisas, conduzidas pelo sociólogo Nels Anderson, foram patrocinadas pelo governo militar dos EUA na Alemanha 
Ocidental (WIGGERSHAUS, 1993, p. 440) e, em seguida, pela Unesco. Ambos os filósofos também desempenharam papéis de importadores de métodos das ciências sociais empíricas, sobretudo os desenvolvidos por Lazarsfeld na Universidade de Columbia: o Instituto de Frankfurt foi, de fato, o correspondente para o Bureau for Applied Social Research, dirigido por Paul Lazarsfeld (WHEATLAND, 2005).

Além disto, o instituto desenvolveu diversos trabalhos em sociologia das relações industriais e em psicologia social, com o intuíto de recuperar as técnicas empíricas que, durante muito tempo, foram reservadas aos estudos de mercado (HORKHEIMER, 1952, p. viii). Como havia feito nos Estados Unidos, em 1937, quando ele inventava a "teoria crítica", Horkheimer pretendeu conciliar a filosofia alemã da sociedade e das ciências sociais com "os mais avançados métodos empíricos da sociologia americana moderna" "13. Em cartas onde buscava patrocinadores, o diretor do Instituto elogiou a utilização potencial dos métodos empíricos norte-americanos para a modernização racional da sociedade e da economia alemã (WIGGERSHAUS, 1993, p. 422).

Horkheimer e Adorno serviram de intermediários não apenas entre a Alemanha, em processo de reconstrução, e os Estados Unidos, mas também entre a filosofia e as ciências sociais, e essa posição determinou, paralelamente e progressivamente, segundo os lucros simbólicos, uma certa distância em relação a seus próprios argumentos anteriores em favor das ciências sociais empíricas. A partir de 1955, Adorno começou a denunciar, sistematicamente, algumas técnicas de investigação, assimilando-as ao ex-inimigo da "teoria crítica": a epistemologia positivista. Ao mesmo tempo em que ele defendia a prática das pesquisas de campo, sob determinadas condições, Adorno nunca se mostrou um verdadeiro sociólogo (Ibid., p. 449). Esta resistência constante às ciências sociais se manifestou novamente, no pós-guerra, através de uma crítica seletiva de alguns métodos importados, como, por exemplo, entrevistas grupais ou pesquisas de opinião.

A "disputa do positivismo" entre Adorno e Popper e seus alunos ou colaboradores, ocorrida durante o Congresso da Deutsche Gesellschaft für Soziologie de 1961, foi o resultado deste distanciamento lento do papel

13 Max Horkheimer. Memorandum über das Institut für Sozialforschung an der Universität Frankfurt-am-Main, 1950 (cité dans WIGGERSHAUS, 1993, p. 422). 
de passador dos métodos americanos de pesquisa à Alemanha (ADORNO et al., 1979). Os pronunciamentos de Adorno, durante esta disputa, apresentaram inflexões idênticas às de Horkheimer, em seu texto de 1937, e o mesmo combate contra o positivismo e a "pesquisa administrativa." Mas esses debates só foram publicados em 1968, quando reapareceu a própria ideia de "teoria crítica".

\section{Mediação e identidade}

Porém, seria errado interpretar o desaparecimento temporário da etiqueta como uma reação de sobrevivência, ou como uma estratégia, consciente ou inconscientemente pertinente, frente a uma experiência individual de desajustamento em relação aos meios sociais dominantes, norte-americanos ou alemães, hostis à crítica social e ao espírito marxista da "teoria crítica". A explicação psicológica dos mecanismos de rejeição da etiqueta pela interiorização de limitações externas foi secundária. A posição em que Adorno e Horkheimer foram colocados deve-se ao exílio e ao retorno do exílio. Com efeito, esta posição levantou, por natureza, questões de identificação (JEANPIERRE, 2004).

Questões de identificação nacional, por exemplo, que podiam ser traduzidas pela escolha de uma nacionalidade, de um idioma de expressão, ou pela decisão de retorno ao país de origem após o exílio. Mas, também, questões mais gerais de identificação subjetiva em relação aos diferentes status sociais ocupados pelos intelectuais exilados. Essas escolhas de identificação não constituíam dados de ordem psicológica, mas foram configuradas por conflitos entre filiações múltiplas e demandas sociais.

Com efeito, tudo se passou como se esses comportamentos tivessem contrabalançado as estratégias de resistência a uma desclassificação social importante no exílio e, em seguida, as estratégias para uma reclassificação ascendente, não menos importante no retorno ao país: independentemente da mobilidade social em jogo, o interesse ou a necessidade de eles não fazerem críticas públicas e de não aparecerem como "teórico crítico" foram mais fortes do que o interesse ou a necessidade opostos. Mas essas restrições de identificação refletiam, principalmente, em ambas as situações, uma grande 
discrepância entre a dependência objetiva dos estudiosos alemães exilados em relação aos acadêmicos norte-americanos, durante o período do exílio e do pós-guerra, e a sensação subjetiva de superioridade intelectual relacionada à afiliação à tradição acadêmica alemã, mais antiga e mais reconhecida, entre as duas guerras mundiais, do que a tradição acadêmica americana.

Uma vez abandonada a escala nacional de análise, o constante recalque da designação "teoria crítica" pôde remeter a uma posição social que era também constante, embora experimentada de maneira subjetiva, sob modalidades opostas: a posição de mediador ou de intermediário entre as sociedades americana e alemã, particularmente entre os mundos acadêmicos dos dois países. O recalque, quase imediato, da etiqueta "teoria crítica" após sua criação foi também uma invenção transatlântica. Isso também valeu para a sua reinvenção, a partir do final da década de 1960.

\section{O mito transatlântico da "Teoria Crítica"}

O renascimento, em várias línguas, da designação de "Teoria Crítica", ocorrido simultaneamente, por volta do ano de 1968, na Alemanha e nos Estados Unidos, foi de fato inseparável da estrutura assimétrica entre os dois Estados e esses dois mundos acadêmicos nacionais. Enquanto Horkheimer havia proibido a publicação de praticamente todos os textos produzidos pelo Instituto antes de 1950 e, desse modo, havia procurado construir uma imagem aceitável para o establishment da nova República Federal da Alemanha Ocidental, surgia nos Estados Unidos uma representação politizada das atividades intelectuais dos membros do Institut für Sozialforschung - enfatizando a crítica da modernidade e as origens dessa análise marxista ${ }^{14}$-, notadamente pelas posições adotadas por Adorno e Horkheimer, durante o exílio norte-americano.

A imagem de Adorno e de Horkheimer, enquanto teóricos críticos dos efeitos das indústrias culturais, da "pesquisa administrativa" em sociologia e

14 Sobre as condições sociais gerais desta representação, não exclusivamente ligadas ao mercado intelectual, Jay sugere que a análise marxista é particularmente compatível com a sociedade americana, onde não existe uma classe operária organizada, como na Europa (1986, p. 126). 
da sociedade americana, foi proposta, em 1950, por uma série de intelectuais progressistas norte-americanos, como os sociólogos C. Wright Mills ou David Riesman, que se opuseram ao predomínio crescente dos métodos quantitativos, defendidos por Lazarsfeld na Universidade de Columbia (JAY, 1977; WHEATLAND, 2003). Nesse contexto geral dominante de releitura norte-americana da "Escola de Frankfurt", a oposição de Adorno aos métodos de Lazarsfeld foi construída pela sociologia americana e confirmada por Adorno, a partir de um depoimento publicado nos Estados Unidos, em 1969, em um livro escrito por historiadores, sobre a emigração de cientístas germanófonos para os Estados Unidos, após 1933 (FLEMING; BAILYN, 1969; ADORNO, 2003b, p. 265-300). Os primeiros trabalhos históricos sobre a "Escola de Frankfurt", como o estudo pioneiro de Martin Jay, também confirmaram essa imagem de teóricos críticos, vistos como os precursores, até mesmo no exílio, de uma crítica à sociedade americana e europeia, e considerados profetas pelos estudantes universitários da Nova Esquerda no mundo inteiro.

Os estudantes críticos alemães, mobilizados durante a década de 1960, compartilharam então a mesma representação da "Escola de Frankfurt", embora essa representação não coincida mais com o ensino e com as produções do Instituto. Parte do movimento estudantil alemão, em Frankfurt e em Berlim, divulgava os textos de Adorno e de Horkheimer, anteriores a 1950, e se identificava com esses textos para denunciar não só a crise da universidade e as relações sociais na sociedade da Alemanha Ocidental, mas também a influência americana na Europa e a guerra no Vietnam. Em ambos os lados do Atlântico, os textos escritos durante a República de Weimar e, sobretudo, no exílio, foram instrumentalizados para criticar os Estados Unidos e sua política (WIGGERSHAUS, 1993, p. 592-616). Essa utilização e essa operação de identificação da "Escola de Frankfurt" à "teoria crítica" - unicamente - não correspondiam à percepção de Adorno e de Horkheimer sobre o projeto intelectual do Instituto. A reativação das etiquetas "Kritische Theorie" e "Critical Theory" em alemão e em inglês foi, precisamente, a resposta dada pelos dois filósofos a essa discrepância vivenciada por eles, entre a representação produzida pela recepção de seus escritos entre as mais jovens gerações progressistas alemães e americanas e a representação que eles tinham de si mesmos. Problemas de identificação, ainda, como durante o exílio, entendidos como problemas de discordância entre a identidade para si e a identidade para o Outro. 
A "invenção da tradição" da "teoria crítica" foi elaborada, em primeiro lugar, pela reedição, por Adorno e Horkheimer, dos textos dos mesmos, considerados os mais críticos ou marxistas nas décadas de 1930 e de $1940^{15}$. De fato, desde o início dos anos 1960, Horkheimer se irritou com a proliferação de edições piratas dos textos e com a manipulação frequente, pelos estudantes universitários alemães, das citações extraídas desses escritos para justificar suas ações políticas e para criticar os colegas mais velhos do Instituto (WIGGERSHAUS, 1993, p. 607) ${ }^{16}$. Segundo ele, os jovens estudantes universitários rebeldes traíram o sentido da "teoria crítica" e entraram em contradição com ela.

Sabemos que, em janeiro de 1969, Adorno mandou fechar o Instituto ocupado pelos estudantes de Sociologia e de Filosofia, pela polícia, e criticou, em nome da autonomia da atividade teórica, a utilização ativista e, segundo ele, instrumental de seus textos pelos alunos críticos. A fim de permanecer fiel ao seu espírito, disse Horkheimer, a "teoria crítica" devia se afastar de Marx e defender o "mundo livre [...] contra todas as formas de fascismo - Hitler, Stalin ou outros", pois "o seu naufrágio no oceano do poder brutal significaria também o fim da civilização da qual a teoria crítica ainda faz parte" (HORKHEIMER, 1974, p. 13). A reinvenção da "teoria crítica" significou também uma reescrita da história da "Escola de Frankfurt" para melhor alinhar a memória coletiva dos atos passados à nova designação geral do Instituto. Um bom exemplo, entre outros, foi a recusa de Adorno em publicar, nas suas obras completas, a pesquisa sobre a rádio e a música, no início da década de 1940, realizada depois de sua crítica à "pesquisa administrativa", no contexto da investigação dirigida por Lazarsfeld (FLECK, 2007, p. 327-329).

Essa revisão do passado estava ligada, sobretudo, à história do exílio norte-americano do Instituto e à atividade de Adorno e de Horkheimer na Alemanha do pós-guerra. A iniciativa de Horkheimer de usar novamente

15 A leitura dos prefácios de Max Horkheimer e Theodor W. Adorno, acrescentados às reedições de Kritische Theorie e de Dialektik der Aufklärung, em 1969, confirma a característica interesseira e reativa dessa reinvenção.

16 "A aplicação precipitada e dogmática da teoria crítica à práxis, em uma realidade histórica que não é mais a mesma, só poderia acelerar o processo que deveria ser denunciado. Aqueles que pensam que a teoria crítica é um compromisso sério, especialmente Adorno, que a desenvolveu comigo, concordam neste ponto" (HORKHEIMER, 1974, p. 7-8). 
a etiqueta "teoria crítica", no final dos anos 1960, na Alemanha, pretendia reapropriar um recurso simbólico, inicialmente ignorado pelo Instituto e, em seguida, monopolizado de maneira subterrânea pelos movimentos estudantis alemães e americanos do período. Tratava-se também de lutar contra Marcuse - que permaneceu nos Estados Unidos, mas que era popular entre os estudantes críticos alemães desde 1964 - e os intelectuais progressistas americanos que afirmavam se inspirar nos mesmos textos.

Para entendermos o surgimento da chamada "Critical Theory" nos Estados Unidos, no mundo editorial e intelectual do final dos anos 1960, tivemos de desviar para a história do Institut für Sozialforschung de Frankfurt, em particular em busca dos conflitos provocados pela designação de seu projeto coletivo intelectual. Esta produção transatlântica, tanto alemã como americana, dos anos 1960, objeto de lutas para se definir a etiqueta da "Teoria Crítica" constituiu, naquele momento, a reinvenção de uma invenção de Horkheimer, da década de 1930, e, desde então, produzida em um contexto já transatlântico, o do exílio do Instituto nos Estados Unidos.

Nosso objetivo foi esclarecer um aspecto paradoxal, no entanto, despercebido da circulação geográfica e histórica dessa designação: o seu desaparecimento, provocado pelo próprio inventor, entre o final dos anos 1930 e o final dos anos 1960. O fato de Horkheimer e Adorno, como Bartleby, não terem se apresentado como teóricos críticos, durante esse período, siginificava, pelo contrário, que a estrutura dos interesses dos produtores-exportadores, ao lado da estrutura dos agentes importadores, era fundamental para entender os mecanismos da circulação internacional das ideias.

Essa abordagem convida também o pesquisador a examinar as condições de validade da distinção analítica entre as estruturas de interesse, partindo de escalas nacionais (ou locais) independentes umas das outras. Quando não há cancelamento das diferenças nacionais - neste caso, entre estruturas dos meios acadêmicos e mercados intelectuais alemães e norte-americanos -, há uma possibilidade de introduzir as relações de poder internacionais como uma variável adicional, agindo sobre os comportamentos existentes nos espaços nacionais e transnacionais. O exílio e o retorno do exílio produzem, nesses espaços, posições de intermediários internacionais, interculturais e conflitos de afiliação e de identificação, restrições específicas já destacadas. 
O desaparecimento do rótulo "Teoria Crítica" nos Estados Unidos e seu reaparecimento na Alemanha, na década de 1960, surgiu então para responder às contradições, vivenciadas em razão dessa posição de intermediário dos protagonistas. A designação "Teoria Crítica" funcionou como um recurso simbólico para alinhar uma oferta intelectual sobre uma demanda social incompatível e para manter uma identidade estável, apesar de uma discrepância entre identidade para si mesmo e identidade para o Outro.

Em uma escala subjetiva e individual, essa estratégia sinaliza a existência de um efeito de hegemonia, exercido pela universidade americana e suas modalidades de organização, em relação aos acadêmicos e à universidade alemã. A partir da década de 1940, esse efeito foi indissociavelmente um produto de mecanismos políticos nas relações internacionais e das lógicas específicas dos intercâmbios científicos globais. Desaparecimentos e renascimentos da designação "Teoria Crítica" foram operados ao longo do período estudado, através das relações de poder transnacionais que mudaram de direção e de intensidade, entre os anos 1930-1940 e 1950-1960.

Por isso, Horkheimer e Adorno foram capazes, sem se contradizerem a si mesmos, de interpretar o mundo americano do exílio, a partir de visões europeias e alemãs, e de olhar a Alemanha Ocidental, no período de sua reconstrução, com uma percepção profunda, afetada pela estadia na América e pelo que eles aprenderam lá (JAY, 1986, p. 126). No entanto, a história das teorias, das filosofias e das ciências humanas e sociais em geral foi escrita dentro de um contexto nacional. Esse estudo de casos mostra a importância de uma abordagem transnacional desses objetos ${ }^{17}$. A coprodução dos objetos simbólicos não exclui a assimetria das relações entre os protagonistas e suas capacidades de apropriação dos produtos coletivos. Certamente, desse ponto de vista, os Estados Unidos têm servido, ao mesmo tempo, de imposição hegemônica e de "operador de universalização" (AMSELLE, 2001) para a circulação da "Teoria Crítica", da década de 1930 aos dias de hoje ${ }^{18}$.

(2008).

17 Para um esboço sobre a história das ciências sociais, ver Heilbron, Guilhot e Jeanpierre

18 Aliás, um comentarista norte-americano (Paul Piccone) observou, na década de 1970, que a "teoria crítica" estava se desenvolvendo no mundo anglófono, enquanto que na Alemanha ela tendia a desaparecer ou a mudar de forma, e que a ciência social norte-americana dos anos 1950 começava a exercer lá sua supremacia. 
Isso também se aplica a muitos outros produtos simbólicos europeus, na segunda metade do século XX: sabemos melhor agora "como Nova York tem roubado a ideia da arte moderna" (GUILBAULT, 1988) ou como as universidades norte-americanas têm coproduzido a "French Theory" (CUSSET, 2003; LAMONT, 1987). Mostramos aqui como Adorno e Horkheimer foram forçados a abandonar e reinventar a "Teoria Crítica", na Alemanha e nos Estados Unidos, na década de 1960. A história da Critical Theory, após a década de 1970, terá de ser escrita a partir de então.

\section{Referências}

ABENSOUR, Miguel. La Théorie critique: une pensée de l'exil. Archives de philosophie, v. 45, n. 2, p. 179-200, 1982.

ADORNO, Theodor W. Modèles critiques. Interventions, répliques. Paris: Payot, 2003a.

. Briefe und Briefwechsel, 5: Briefe an die Eltern, 1939-1951. Frankfurtam-Main: Suhrkamp, 2003b.

et al. De Vienne à Francfort. La querelle allemande des sciences sociales. Bruxelles: Complexe, 1979.

ALBRECHT, Clemens et al. The Intellectual Foundation of the Federal Republic. A History of the Influence of the Frankfurt School. Frankfurt-New York: Campus, 1999.

AMSELLE, Jean-Loup. Branchements. Anthropologie de l'universalité des cultures. Paris: Flammarion, 2001.

APPADURAI, Arjun. [2001]. Après le colonialisme. Les conséquences culturelles de la globalisation. Paris: Payot \& Rivages, 2005.

ASH, Mitchell G.; SÖLLNER, Alfons (Eds.). Forced Migration and Scientific Change. Emigre German-Speaking Scientists and Scholars after 1933. Washington: German Historical Institute; Cambridge: Cambridge University Press, 1996.

ASSAYAG, Jackie. La culture comme fait social global? Anthropologie et (post) modernité. L'Homme, v. 148, p. 201-224, 1998.

. L'Asie du Sud "made in the USA": transferts culturels, institutions universitaires et diaspora intellectuelle. L'Homme, v. 156, p. 99-130, 2000. 
ASSOUN, Paul-Laurent. L'École de Francfort. Paris: Presses Universitaires de France (“Que sais-je?”), 1987.

BASTIDE, Roger. Sociologie et littérature comparée. Cahiers Internationaux de Sociologie, v. 17, p. 93-100, 1954.

. Le principe de coupure et le comportement afro-brésilien. In: CONGRESSO INTERNACIONAL DE AMERICANISTAS, 31., 1954. Anais. São Paulo: Anhembi, v. I, p. 496-503, 1955.

. Problèmes de l'entrecroisement des civilisations et de leurs œuvres. In: GURVITCH, Georges (Ed.). Traité de Sociologie. Paris: Presses Universitaires de France, v. II, p. 315-330, 1960.

BHABHA, Homi K. The Location of Culture. London-New York: Routledge, 1994. BOLTANSKI, Luc. Note sur les échanges philosophiques internationaux. Actes de la Recherche en Sciences Sociales, v. 5-6, n. 1, p. 191-199, 1975.

BOURDIEU, Pierre. [1990]. Les conditions sociales de la circulation internationale des idées. Actes de la Recherche en Sciences Sociales, v. 145, p. 3-8, 2002.

CLAUSSEN, Detlev. Theodor W. Adorno. Ein letztes Genie. Frankfurt-am-Main: S. Fischer, 2003.

CLIFFORD, James. Routes, Travel and Translation in the Late Twentieth Century. Cambridge: Harvard University Press, 1997.

CUSSET, François. French Theory. Foucault, Derrida, Deleuze \& Cie et les mutations de la vie intellectuelle aux États-Unis. Paris: La Découverte, 2003.

DE SWAAN, Abram. Pour une sociologie de la société transnationale. Revue de Synthèse, 4e série, v. 1, p. 89-111, 1998.

DUBIEL, Helmut. Theory and Politics. Studies in the Development of Critical Theory. Cambridge: MIT Press, 1985.

FLECK, Christian. Transatlantische Bereicherungen. Zur Erfindung der empirischen Sozialforschung. Frankfurt-am-Main: Suhrkamp, 2007.

FLEMING, Donald; BAILYN, Bernard (Eds.). The Intellectual Migration. Europe and America, 1930-1960. Cambridge: Harvard University Press, 1969.

GIOVACCHINI, Saverio. "The Land of Milk and Honey": Anti-Nazi Refugees in Hollywood. Historical Journal of Film, Radio and Television, v. 18, n. 3, p. 437444, 1998.

. Hollywood Modernism. Film and Politics in The Age of The New Deal. Philadelphia: Temple University Press, 2001. 
GRUZINSKI, Serge. La Pensée Métisse. Paris: Fayard, 1999.

GUILBAUT, Serge. Comment New York vola l'idée d'art moderne? Expressionnisme abstrait, liberté et guerre froide. Nîmes: J. Chambon, 1998.

HABERMAS, Jürgen. Drei Thesen zur Wirkungsgeschichte der Frankfurter Schule. In: HONNETH, Axel; WELLMER, Albrecht (Eds). Die Frankfurter Schule und die Folgen. Referate eines Symposiums der Alexander von Humboldt-Stiftung, Dezember 1984. Berlin-New York: De Gruyter, p. 8-12, 1986.

HANNERZ, Ulf. Transnational Connections. Culture, People, Places. London-New York: Routledge, 1996.

HEILBRON, Johan; GUILHOT, Nicolas; JEANPIERRE, Laurent. Toward a Transnational History of the Social Sciences. Journal of the History of the Behavioral Sciences, v. 44, n. 2, p. 146-160, 2008.

HEILBUT, Anthony. [1983]. Exiled in Paradise. German Refugee Artists and Intellectuals in America, from the 1930s to the Present. Berkeley: University of California Press, 1996.

HEINICH, Nathalie. Façons d' "être" écrivain: l'identité professionnelle en régime de singularité. Revue Française de Sociologie, v. 36, n. 3, p. 499-524, 1995.

HORKHEIMER, Max. Survey of the Social Sciences in Western Germany. A Report on Recent Developments. Washington: Library of Congress, Reference Department, European Affairs Division, 1952. $\overline{2 \mathrm{v} .,} 1968$.

Kritische Theorie. Eine Dokumentation. Frankfurt-am-Main: S. Fischer,

. [1970]. Théorie traditionnelle et théorie critique. Trad. de Claude Maillard et Sibylle Muller. Paris: Gallimard, 1974.

; ADORNO, Theodor W. [1944]. La Dialectique de la Raison. Fragments Philosophiques. Trad. d'Éliane Kaufholz. Paris: Gallimard, 1974.

HUGHES, H. Stuart. The Sea Change. The Migration of Social Thought, 1930-1965. New York: Harper \& Row, 1975.

JÄGER, Lorenz. Adorno. Eine politische Biographie. München: Deutsche VerlagsAnstalt. 2003.

JAY, Martin. [1973]. L'Imagination dialectique. L'École de Francfort, 1923-1950. Paris: Payot, 1977.

. Permanent Exiles. Essays on the Intellectual Migration from Germany to America. New York: Columbia University Press, 1986. 
JEANPIERRE, Laurent. Une opposition structurante pour l'anthropologie structurale: Lévi-Strauss contre Gurvitch, la guerre de deux exilés français aux États-Unis. Revue d'Histoire des Sciences Humaines, v. 11, p. 13-44, 2004.

JENEMANN, David. Adorno in America. Minneapolis: University of Minnesota Press, 2007.

KATZ, Barry. Foreign Intelligence. Research and Analysis in the Office of Strategic Services, 1942-1945. Cambridge: Harvard University Press, 1989.

KROHN, Claus-Dieter. [1987]. Intellectuals in Exile. Refugee Scholars and the New School for Social Research. Amherst: University of Massachusetts Press, 1993.

LAMONT, Michèle. How to Become a Dominant French Philosopher: The Case of Jacques Derrida. American Journal of Sociology, v. 93, n. 3, p. 584-622, 1987.

LAZARSFELD, Paul F. Remarks on Administrative and Critical Communications Research. Studies of Philosophy and Social Sciences, v. 9, n. 1, p. 2-16, 1941.

. An Episode in the History of Social Research. In: FLEMING, D.; BAILYN, B. (Eds). The Intellectual Migration. Europe and America, 1930-1960. Cambridge: Harvard University Press, p. 270-337, 1969.

MORRISON, David E. Kultur and Culture: The Case of Theodor W. Adorno and Paul F. Lazarsfeld. Social Research, v. 45, n. 2, p. 331-355, 1978.

MÜLLER-DOOHM, Stefan. Adorno. Une biographie. Paris: Gallimard, 2004.

POLLAK, Michael. Paul F. Lazarsfeld, fondateur d'une multinationale scientifique. Actes de la Recherche en Sciences Sociales, v. 25, p. 45-49, 1979.

. Max Weber en France. L'itinéraire d'une ouvre. Paris: Institut d'Histoire du Temps Présent/Centre National de la Recherche Scientifique (Cahiers de l'IHTP, 3), 1986.

. [1984]. Vienne 1900. Une identité blessée. Paris: Gallimard (Folio), 1992. . L'Experience concentrationnaire. Essai sur le maintien de l'identité sociale. Paris: Métailié, 2000.

ROSENTAL, Paul-André. Maintien/rupture: un nouveau couple pour l'analyse des migrations. Annales. Économies Sociétés Civilisations, v. 45, n. 6, p. 1403-1431, 1990.

SCHMIDT, James. The Eclipse of Reason and the End of the Frankfurt School in America. New German Critique, v. 34, n. 1, p. 47-76, 2007.

SCHÜTZ, Alfred. L'Étranger. Un essai de psychologie sociale. Trad. de Bruce Bégout. Paris: Allia, 2003. 
SÖLLNER, Alfons. Geschichte und Herrschaft. Studien zur materialistischen Sozialwissenschaft, 1929-1942. Frankfurt-am-Main: Suhrkamp, 1979.

. Adorno und die politische Kultur der frühen Bundesrepublik. Mittelweg 36, v. 11, n. 2, p. 37-52, 2002.

. "Political Culturalism?" Adorno's "Entrance" in the Cultural Concert of West-German Postwar History. In: KETLER, David; LAUER, Gerhard (Eds.). Exile, Science, and Bildung. The Contested Legacies of German Emigre Intellectuals. New York: Palgrave Macmillan, p. 185-200, 2005.

VANDERBERGHE, Frédéric. Une histoire critique de la sociologie allemande, 2: Horkheimer, Adorno, Marcuse, Habermas: aliénation et réification. Paris: La Découverte-Mauss, 1998.

WHEATLAND, Thomas. Isolation, Assimilation and Opposition. A Reception History of the Horkheimer Circle in the United States, 1934-1979. History PhD, Boston College, 2003.

. The Frankfurt School's Invitation from Columbia University: How the Horkheimer Circle Settled on Morningside Heights? German Politics and Society, v. 22, n. 3, p. 1-32, 2004a.

. Critical Theory on Morningside Heights: From Frankfurt Mandarins to Columbia Sociologists. German Politics and Society, v. 22, n. 4, p. 57-87, 2004 b.

. Not-Such-Odd Couples: Paul Lazarsfeld and the Horkheimer Circle on Morningside Heights. In: KETLER, David; LAUER, Gerhard (Eds.). Exile, Science, and Bildung. The Contested Legacies of German Emigre Intellectuals. New York: Palgrave Macmillan, p. 169-184, 2005.

WIGGERSHAUS, Rolf. [1986]. L'École de Francfort. Histoire, développement, signification. Paris: Presses Universitaires de France, 1993.

Recebido em abril de 2010. Aprovado em abril de 2010. 
